Recepción: 20 / 04 / 2017

Aceptación: 20 / 05 / 2017

Publicación: 15 / 07 / 2017

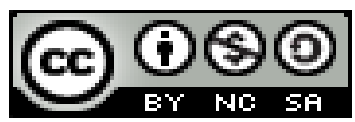

Ciencias Técnicas y aplicadas Artículo Científico

\title{
Implementación del rescate de edificios que son clasificados como patrimonio arquitectónico histórico de la ciudad de Guayaquil
}

\author{
Implementation the rescue of buildings that are classified as historical \\ architectural heritage of the city of Guayaquil
}
Implementação el resgate de edifícios são classificadas como património arquitectónico histórico da cidade de Guayaquil

\author{
María C. Sotomayor-Navarro ${ }^{\mathrm{I}}$ \\ carolina.sotomayorn@ug.edu.ec \\ Magaly N. Sánchez-Lascano II \\ magaly.sanchezl@ug.edu \\ Santiago F. Tisalema-Sáenz ${ }^{\text {III }}$ \\ tisalema@yahoo.com \\ José R. Escobar-Pérez ${ }^{\text {IV }}$ \\ jrep78@gmail.com
}

Correspondencia: carolina.sotomayorn@ug.edu.ec

\footnotetext{
I. Arquitecta; Universidad de Guayaquil, Guayaquil, Ecuador.

II. Diploma Superior en Diseño Curricular por Competencias; Magister en Docencia Universitaria e Investigación Educativa; Profesor de Segunda Enseñanza con Especialización en Lengua Inglesa y Lingüística; Profesor de Segunda Enseñanza con Especialización en Lengua Inglesa y Lingüística; Licenciada en Ciencias de la Educación Especialización: Lengua Inglesa y Lingüística; Universidad de Guayaquil, Guayaquil, Ecuador. 
María C. Sotomayor-Navarro; Magaly N. Sánchez-Lascano; Santiago F. Tisalema-Sáenz; José R. Escobar-Pérez

\section{Resumen.}

La ciudad de Guayaquil ha cumplido su desarrollo urbano de manera fraccionada, por las diversas situaciones acontecidas a lo largo de su historia, que no le permitieron un registro constante y fluido de su crecimiento a través de los tiempos hasta la actualidad. Los numerosos ataques e invasiones piratas y constantes incendios suscitados con mayor vehemencia durante los siglos XVII y XVIII no le permitieron a esta urbe guardar correctamente su registro de identidad y autonomía histórica por la constante destrucción de sus evidencias históricas y edificaciones de épocas pasadas.

Incluso en la actualidad, Guayaquil aqueja de este mal. Pues no se tiene un adecuado control por parte del Municipio de la ciudad, para la protección de bienes inmuebles que registran importancia histórica local. Edificaciones del siglo XVIII y XIX, en buenas condiciones, e incluso, albergues de memorias e identidad guayaquileñas, son a menudo destruidos, derribados, para dar paso a construcciones modernas, pero sin contenido de identidad absoluto.

Sectores e incluso barrios enteros, que en sus emplazamientos y terrenos tenían excelentes ejemplares de edificaciones, casas y residencias de arquitectura moderna y colonial, son constantemente "remodeladas", "reconstruidas", dañando por completo los conceptos bajos los cuales fueron concebidos muy idóneamente dentro de su tiempo. Y todas estas „reconstrucciones ${ }^{\text {ee }}$ suceden con la venia y aprobación del municipio de la ciudad.

Es necesario e imperante la realización de una estudio y análisis de las diferentes edificaciones y sectores que son portadores de la riqueza arquitectónica y de la identidad guayaquileña, para elaborar un documento de rescate patrimonial para presentar como propuesta al M.I. Municipalidad de Guayaquil.

Palabras Clave: Desarrollo urbano; edificaciones; rescate de edificios. 


\section{Abstract.}

The city of Guayaquil has fulfilled its urban development in a fractional way, due to the various situations that have occurred throughout its history, which did not allow a constant and fluid record of its growth through the times until today. The numerous attacks and pirate invasions and constant fires aroused with greater vehemence during centuries XVII and XVIII did not allow this city properly to keep its record of identity and historical autonomy by the constant destruction of its historical evidences and constructions of past times.

Even today, Guayaquil suffers from this evil. For there is not an adequate control by the Municipality of the city, for the protection of real estate that register local historical importance. Buildings of the eighteenth and nineteenth centuries, in good condition, and even shelters of Guayaquil memories and identity, are often destroyed, demolished, to give way to modern constructions, but without absolute identity content.

Sectors and even entire neighborhoods, which in their sites and grounds had excellent examples of buildings, houses and residences of modern and colonial architecture, are constantly "remodeled", "rebuilt", completely damaging the low concepts which were conceived very ideally within Of your time. And all these 'reconstructions' happen with the venia and approval of the municipality of the city.

It is necessary and imperative to carry out a study and analysis of the different buildings and sectors that are bearers of the architectural wealth and Guayaquil identity, in order to prepare a patrimonial rescue document to present as a proposal to M.I. Municipality of Guayaquil.

Keywords: Urban development; buildings; rescue of buildings. 
María C. Sotomayor-Navarro; Magaly N. Sánchez-Lascano; Santiago F. Tisalema-Sáenz; José R. Escobar-Pérez

\section{Resumo.}

A cidade de Guayaquil cumpriu seu desenvolvimento urbano de forma fracionada, devido às várias situações que ocorreram ao longo de sua história, o que não permitiu um registro constante e fluido do seu crescimento através dos tempos até hoje. Os numerosos ataques e invasões de piratas e incêndios constantes despertados com maior veemência durante os séculos XVII e XVIII não permitiram que esta cidade conservasse adequadamente seu histórico de identidade e autonomia pela destruição constante de suas evidências históricas e construções dos tempos passados.

Ainda hoje, Guayaquil sofre com esse mal. Pois não há um controle adequado pelo município da cidade, para a proteção de bens imobiliários que registrem a importância histórica local. Os edifícios dos séculos XVIII e XIX, em boas condições, e até mesmo abrigos de memórias e identidade de Guayaquil, são muitas vezes destruídos, demolidos, para dar lugar a construções modernas, mas sem conteúdo de identidade absoluta.

Setores e até bairros inteiros, que em seus locais e terrenos tinham excelentes exemplos de edifícios, casas e residências da arquitetura moderna e colonial, são constantemente "remodelados", "reconstruídos", prejudicando completamente os conceitos baixos que foram concebidos de forma ideal dentro de seu Tempo. E todas essas "reconstruções" acontecem com o venia e aprovação do município da cidade.

É necessário e imperativo realizar um estudo e análise dos diferentes edifícios e setores que são portadores da riqueza arquitetônica e da identidade de Guayaquil, a fim de preparar um documento patrimonial de resgate para apresentar como proposta para M.I. Município de Guayaquil.

Palavras chave: Desenvolvimento urbano; edifícios; resgate de edifícios. 


\section{Introducción.}

La Arquitectura de Guayaquil inicia con la arquitectura vernácula, que parte de las necesidades de vivienda y del entorno en cual se implanta resolviendo las condiciones de sitio y las necesidades de la cultura de una manera simple y eficiente, analizadas por David Nuremberg "Arquitectura Vernácula en el Litoral", considerando el uso de materiales de la zona, de fácil accesibilidad y con sistemas constructivos que se adaptan al material y condiciones de la zona, demarcado una identidad de la región donde se desarrolla.

En el Ecuador, en comunidades de la sierra, tienden a construirse, desde épocas precoloniales, hábitats de baja altura y poca presencia de vanos, compuesta de materiales como adobe, barro y piedras en sus paredes, techos de paja forradas con adobe o barro, de manera que se pudiera conservar el calor al interior de ellas. (YEPEZ, D. 2012)

En la zona costera del Ecuador, existieron las culturas Huancavilca, Chonos, Punuaes entre otras, que tenían de actividad la pesca, agricultura y comercio. Las construcciones se realizaban de materiales como piedra para cimientos, caña rolliza y Palo prieto para estructuras y paredes. bijao, hoja de caña de azúcar, paja de arroz para cubierta. Es decir con materiales de las zonas.

Construcciones palafíticas que responden a condición de sitio, por sus inundaciones en épocas invernales y que tiene un efecto térmico en el piso ya que se mantiene fresco por la ventilación que ocurre bajo la vivienda. En época de Verano, este "espacio" se lo utilizaba para ocio luego de las jornadas de trabajo y posible almacenamiento. Las paredes construidas con caña picada, permiten el paso tenue de la luz y ventilación, que permite realizar actividades sin necesidad de iluminación artificial o estar expuestos al intenso sol. 
María C. Sotomayor-Navarro; Magaly N. Sánchez-Lascano; Santiago F. Tisalema-Sáenz; José R. Escobar-Pérez

En la cuenca del río Guayas, existieron construcciones vernáculas, una de las principales diferencias son las cubiertas, construidas a cuatro aguas dos de las cuales eran aleros y la construcción de viviendas "flotantes" (sobre el río), que fueron prohibidas por el Cabildo Guayaquileño conocidas como "las balsas" hacia 1748, para 1775 se impuso multa por su uso y para 1826 su prohibición total, que no fueron erradicadas sino hasta 1935-1945 con la construcción de malecones de cemento.

\section{Materiales y métodos.}

Los agentes administrativos locales de Guayaquil, sobre los que recae la responsabilidad y el encargo de la preservación y conservación de bienes patrimoniales, según lo demandado por la Constitución de la República del Ecuador, son el Instituto Nacional de Patrimonio Cultural (INPC) y la Muy Ilustre Municipalidad de Guayaquil. Estas dos entidades públicas deben unir esfuerzos y trabajar en mutua colaboración para el mantenimiento permanente de los patrimonios arquitectónicos.

Estas dos entidades, trabajan a su vez, en estrecha colaboración con fundaciones públicas y privadas, quienes financian y realizan los diferentes proyectos pertinentes a preservación y rehabilitación de bienes en mal estado. Fundaciones como Proyecto 21, Fundación 2000, Junta de Beneficencia de Guayaquil, son las más reconocidas en el ámbito local. 


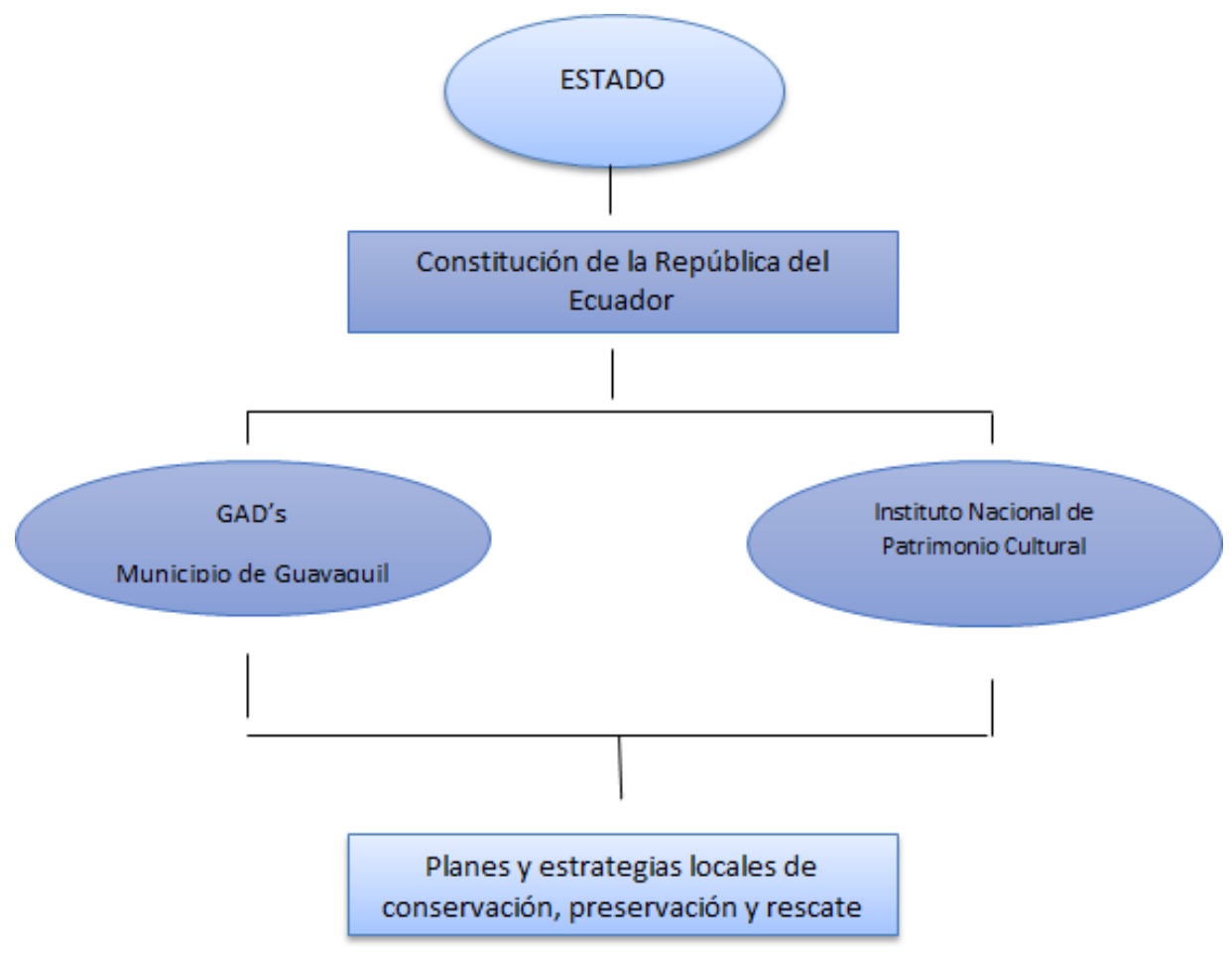

Figura $N^{\circ}$ 1.- Cuadro de agentes e instrumentos legales para la conservación del patrimonio

El órgano encargado del análisis, identificación, tabulación, estudio de condiciones y vigilia por la preservación de los bienes patrimoniales de Guayaquil, es el Instituto Nacional de Patrimonio Cultural (INPC) Regional 5, ubicado en la calle única del barrio patrimonial Las Peñas.

El INPC cuenta con una lista de bienes inmuebles elevados a patrimonio arquitectónico de la ciudad con un total de 637 edificaciones, de diferentes tipología y usos, emplazados en diferentes sectores de la ciudad, de forma no concentrada, por lo que en esta ciudad no se aplica al cien por ciento el concepto de centro histórico o casco antiguo debido a esta disgregación de edificaciones en áreas de centro y oeste de la urbe.

De esta lista, se ha procedido a escoger veinte inmuebles que estén en malas condiciones, abandonados, degradados o deteriorados, ya que representan un peligro para la conservación de la 
María C. Sotomayor-Navarro; Magaly N. Sánchez-Lascano; Santiago F. Tisalema-Sáenz; José R. Escobar-Pérez

identidad de la ciudad, una identidad que se ha vendido perdiendo a lo largo de nuestra historia por diversas razones ya explicadas anteriormente.

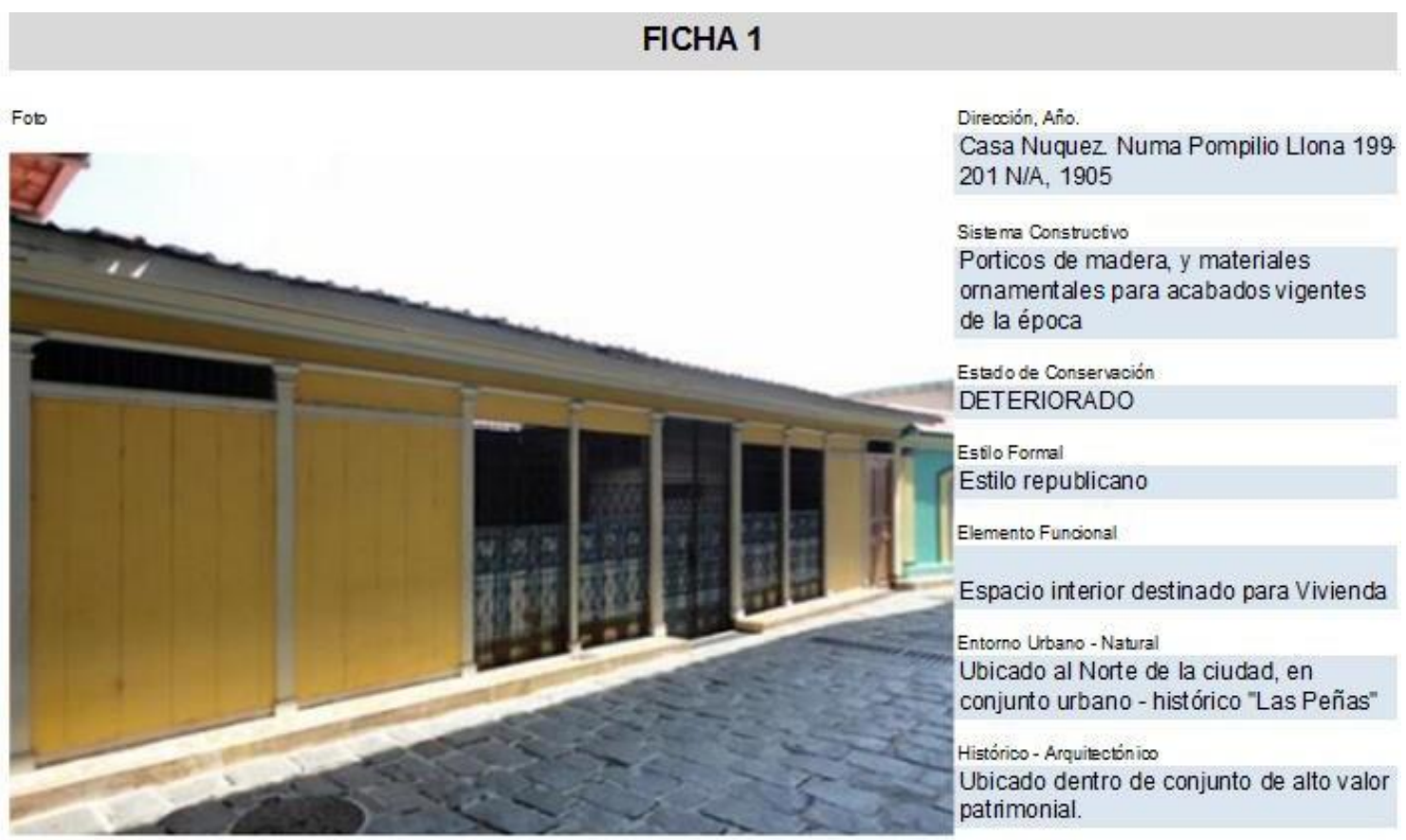


Implementación del rescate de edificios que son clasificados como patrimonio arquitectónico histórico de la ciudad de Guayaquil

\section{FICHA 2}

Foto

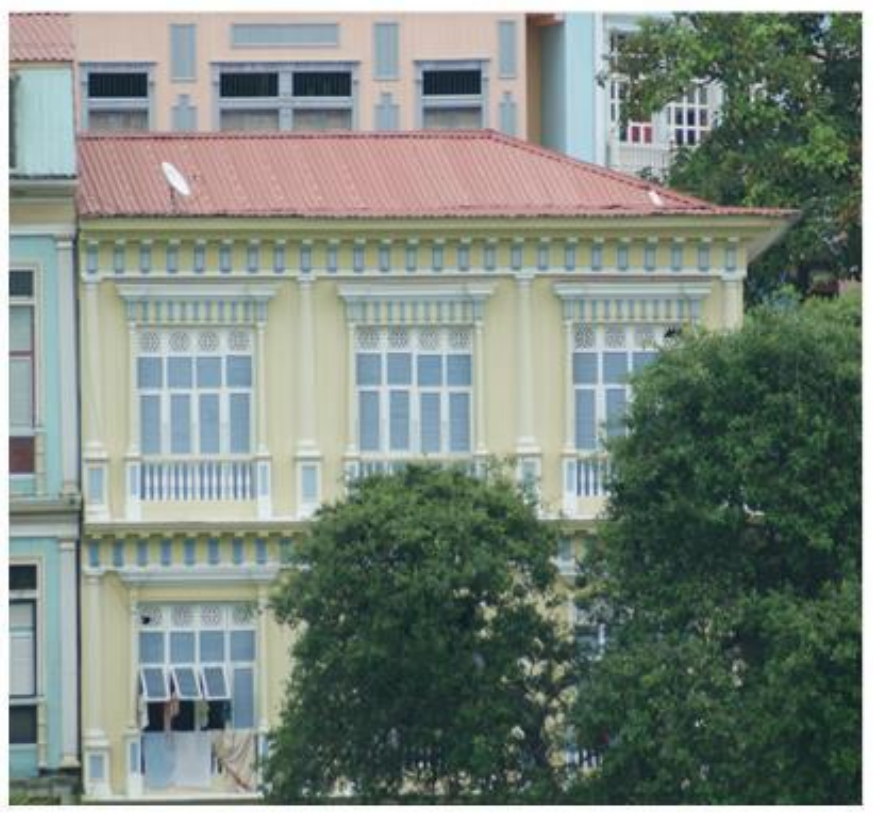

Dirección, Año.

Casa Gonzenbach. Numa Pompilio Uona $157-159$ N/D, 1906

Sistema Constructivo

Porticos de madera, y materiales ornamentales para acabados vigentes de la época

Estado de Conservación ABANDONADO

Estlo Formal

Estilo republicano

Elemento Funcional

Espacio interior destinado para Vivienda

Entorno Urbano - Natural

Ubicado al Norte de la ciudad, en conjunto urbano - histórico "Las Peñas"

Histórico - Arquitectónico

Ubicado dentro de conjunto de alto valor patrimonial.

\section{FICHA 3}

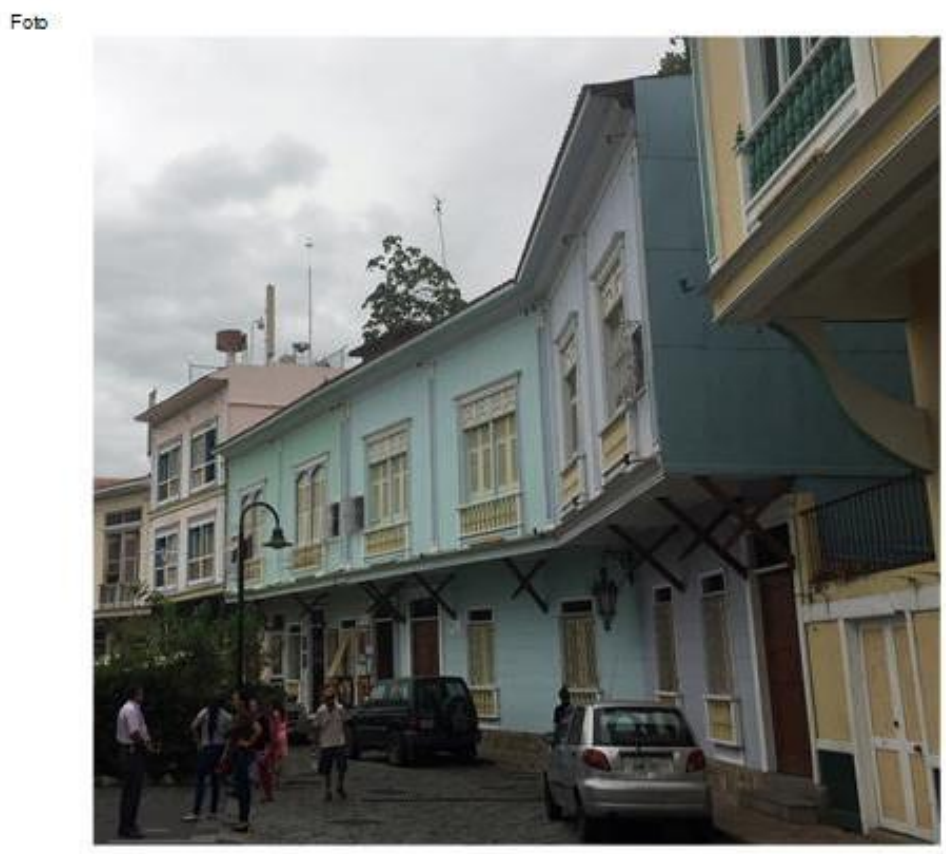

Dirección, Año.

Casa Ituralde. Numa Pompilio Llona 166 - 168 N/D, 1930

Sistema Constructivo

Porticos de madera, y materiales ornamentales para acabados vigentes de la época

Estado de Conservación ABANDONADO

Estio Formal

Estilo republicano

Elemento Funciona

Espacio interior destinado para Vivienda

Entorno Urbano - Natura

Ubicado al Norte de la ciudad, en conjunto urbano - histórico "Las Peñas"

Histórico - Arquitectónico

Ubicado dentro de conjunto de alto valor patrimonial. 


\section{FICHA 4}

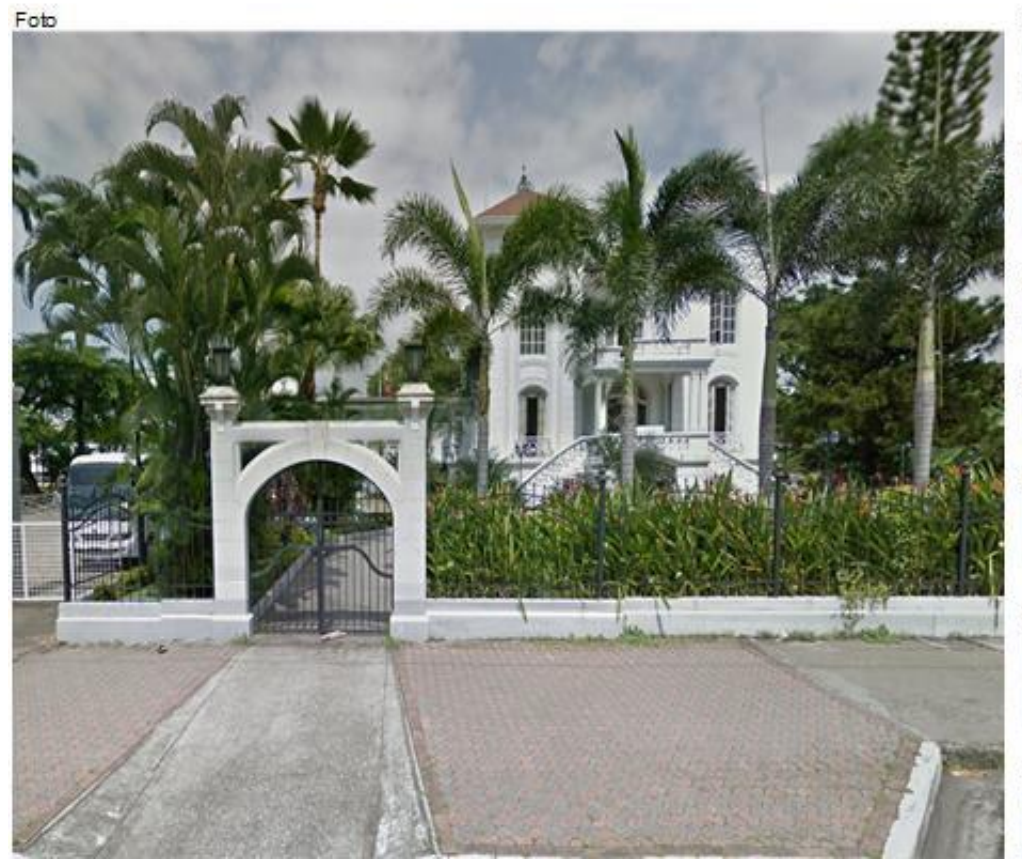

Dirección, Año.

Casa Golagh Virtute. Vacas Galindo 301

y José María Urbina, 1925-1930

Sistema Const uctivo

Porticos de hormigón armado, con

mamposteria de bloques de cemento

Estado de Conservación

ABANDONADO

Estilo Formal

Estilo republicano

Elemento Funcions

Espacio interior destinado para Vivienda

Entorno Urbano - Natural

Ubicado en zona residencial Sur,

incorporada a trama del sector; resalta

su gran magnitud.

Histớrico - Arquitectónico

Constructor Ing. Pedro Manrique

Acevedo

\section{FICHA 5}

\section{Foto}

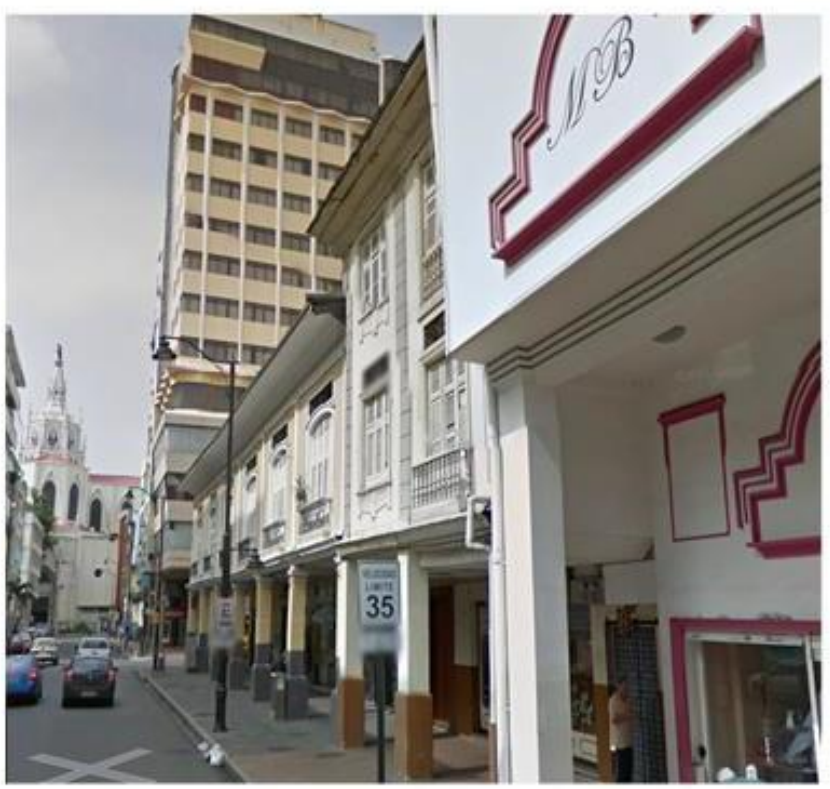

Dirección, Año.

Casa Escobedo \#1416 entre Luque y

Aguirre, $1920-1930$

Sistema Const uctivo

Pórticos de madera.

Estado de Conservación DETERIORADO

Estilo Formal

Estilo republicano

Elemento Funciongl

Espacio interior destinado para

Vivienda, uso de portal al exterior y patio interior.

Entorno Urbano - Natural

Ubicado en zona centro, incorporada a trama del sector.

Histórico - Arquitectónico

Valor Funcional y formal - histórico. 
Implementación del rescate de edificios que son clasificados como patrimonio arquitectónico histórico de la ciudad de Guayaquil

\section{FICHA 6}

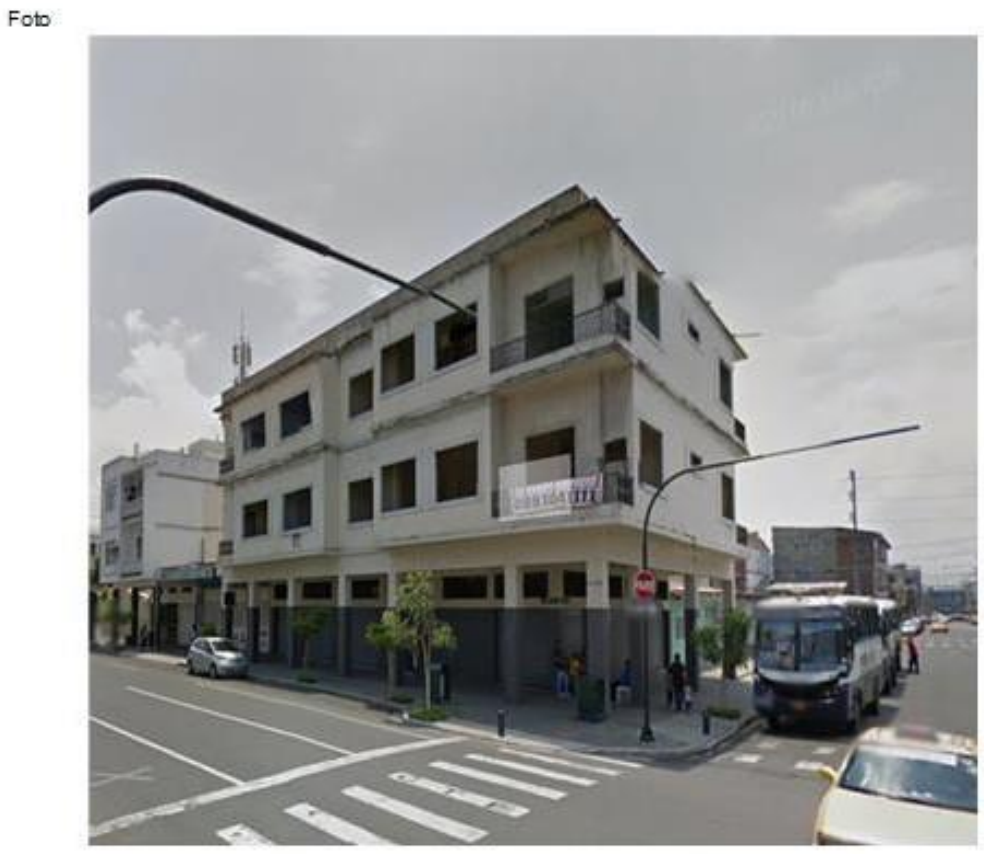

Dirección, Año.

Casa Teresa Castagneto. Chimborazo 2402 y Argentina, 1965

Sistema Const uctivo

Porticos de hormigón armado, con mamposteria de bloques de cemento.

Estado de Conservación ABANDONADO

Estilo Formal

Estilo moderno con simplificación de formas, libre de ornamentos.

Elemento Funcional

Edificio de departamentos con area comercial en planta baja

Entorno Urbeno - Natural

Ubicado en zona centro comercial, incorporada a trama del sector.

Histớrico - Arquitectónico Valor Formal - histórico. 


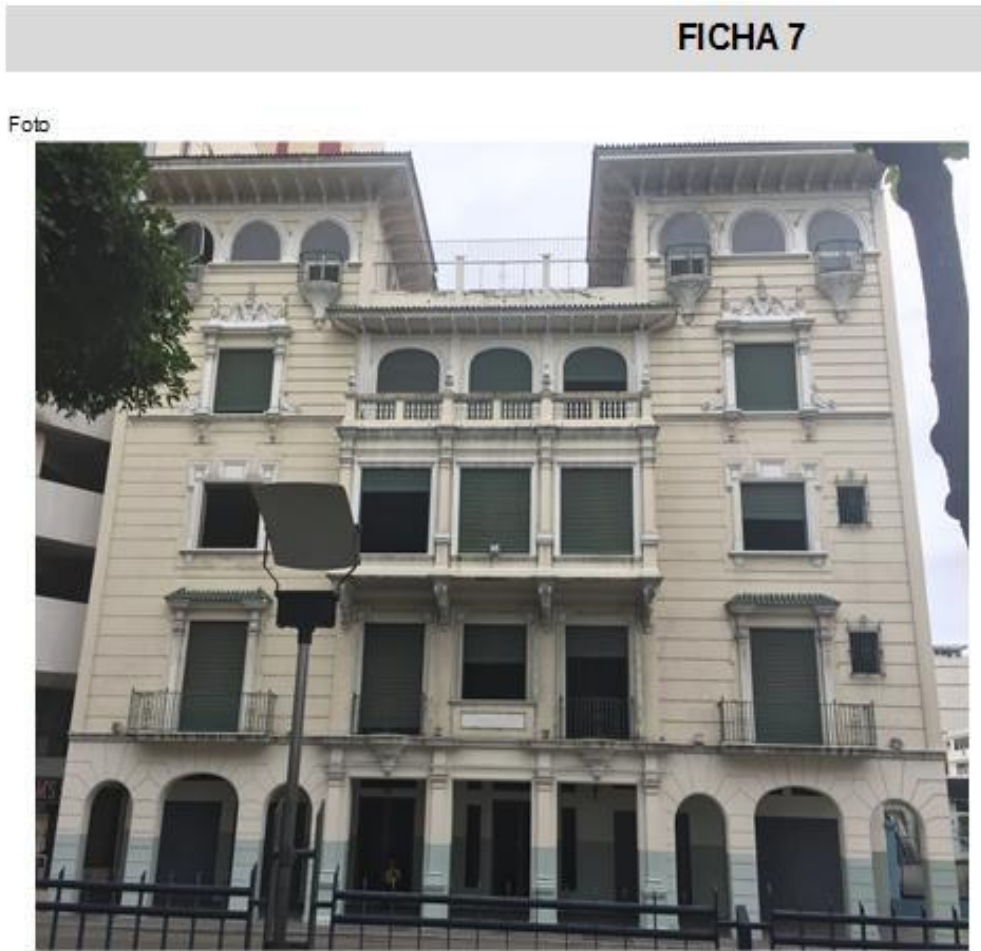

Dirección, Año.

Casona. Malecón Simon Bolivar 02

entre Junin y Roca, 1930-40

Sistema Const uctivo

Porticos, vigas y losas de hormigón armado, con mamposteria de bloques de cemento.

Estado de Conservación ABANDONADO

Estilo Forme

Estilo Republicano

Elemento Funcionsl

Configuración para vivienda con uso de portales.

Entorno Urbano - Natural

Zona central, incorporada a trama del sector, integrado al entorno natural.

Histớico - Arquitectónico

Valor Formal - histórico.

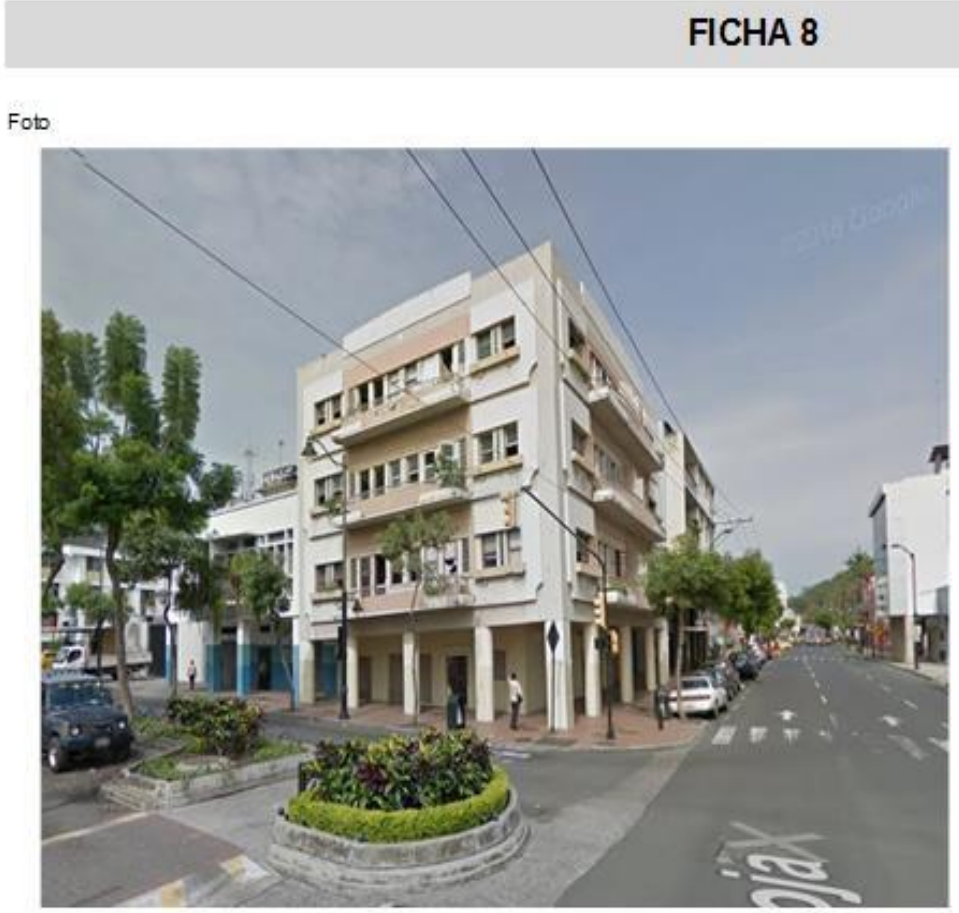

Dirección, Año.

Edificio. Rocafuerte 200 y Loja, 1940

Sistema Constructivo

Porticos, vigas y losas de hormigón armado, con mamposteria de bloques de cemento.

Estado de Conservación DETERIORADO

Estilo Formal

Estilo con influencias Modernas

Elemento Funcional

Edificio de departamentos con area

comercial en Planta Baja.

Entorno Urbeno - Natural

Ubicado en la zona central

Histớico - Arquitectónico

Valor Formal - histórico. 
Implementación del rescate de edificios que son clasificados como patrimonio arquitectónico histórico de la ciudad de Guayaquil

\section{FICHA 9}

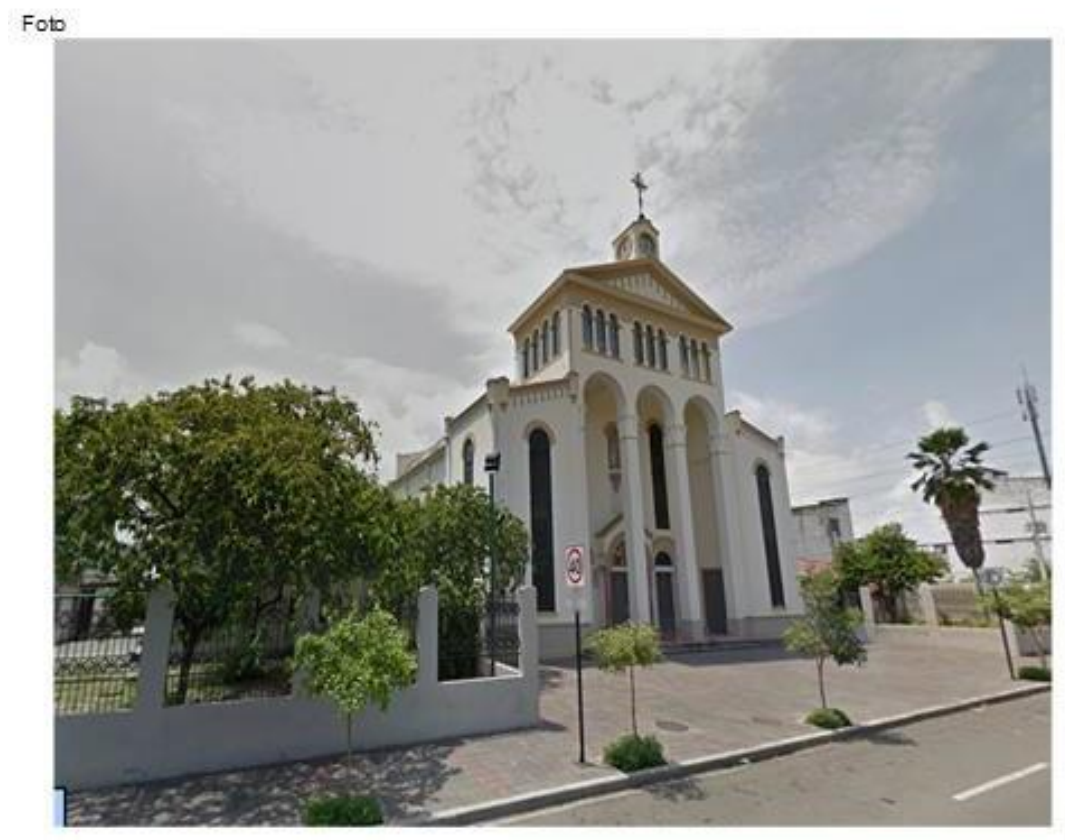

Dirección, Año.

Iglesia Sagrado Corazon de Jesus. Chimborazo 2506 y Portete, 1941-1952

Sistema Constructivo

Porticos, pilotes y losas de hoemigón armado con mamposteria de ladrillo.

Estado de Conservación

\section{DETERIORADO}

Estilo Formal

Estilo Neo-romano.

Elemento Funcionsl

Edificio de departamentos con area comercial en Planta Baja.

Entorno Ur beno - Natural

Ubicado en la zona centro - Sur

Histórico - Arquitectónico

Valor Formal - histórico.

\section{FICHA 10}

Dirección, Año.

Edificio Martinez de Espronceda, Eloy Alfaro 1915 Venezuela. 1930

Sistema Const ructivo

Estructura y losas de hormigón armado, mampostería de ladrillo, pisos de baldosa y mármol

Estado de Conservación DETERIORADO, ABANDONADO

Estilo Formal

estéticos de fortaleza, con torres almenadas, muros con textura tipo sillares.

Elemento Funcional

Diseñado originalmente para uso residencial.

Entorno Ur bano - Natural

Implantado en el área urbana heterogénea en un conjunto de edificaciones de distintas tipología.

Histórico - Arquitectónico

Espronceda por su arquitectura poco convencional 
María C. Sotomayor-Navarro; Magaly N. Sánchez-Lascano; Santiago F. Tisalema-Sáenz; José R. Escobar-Pérez

\section{FICHA 11}

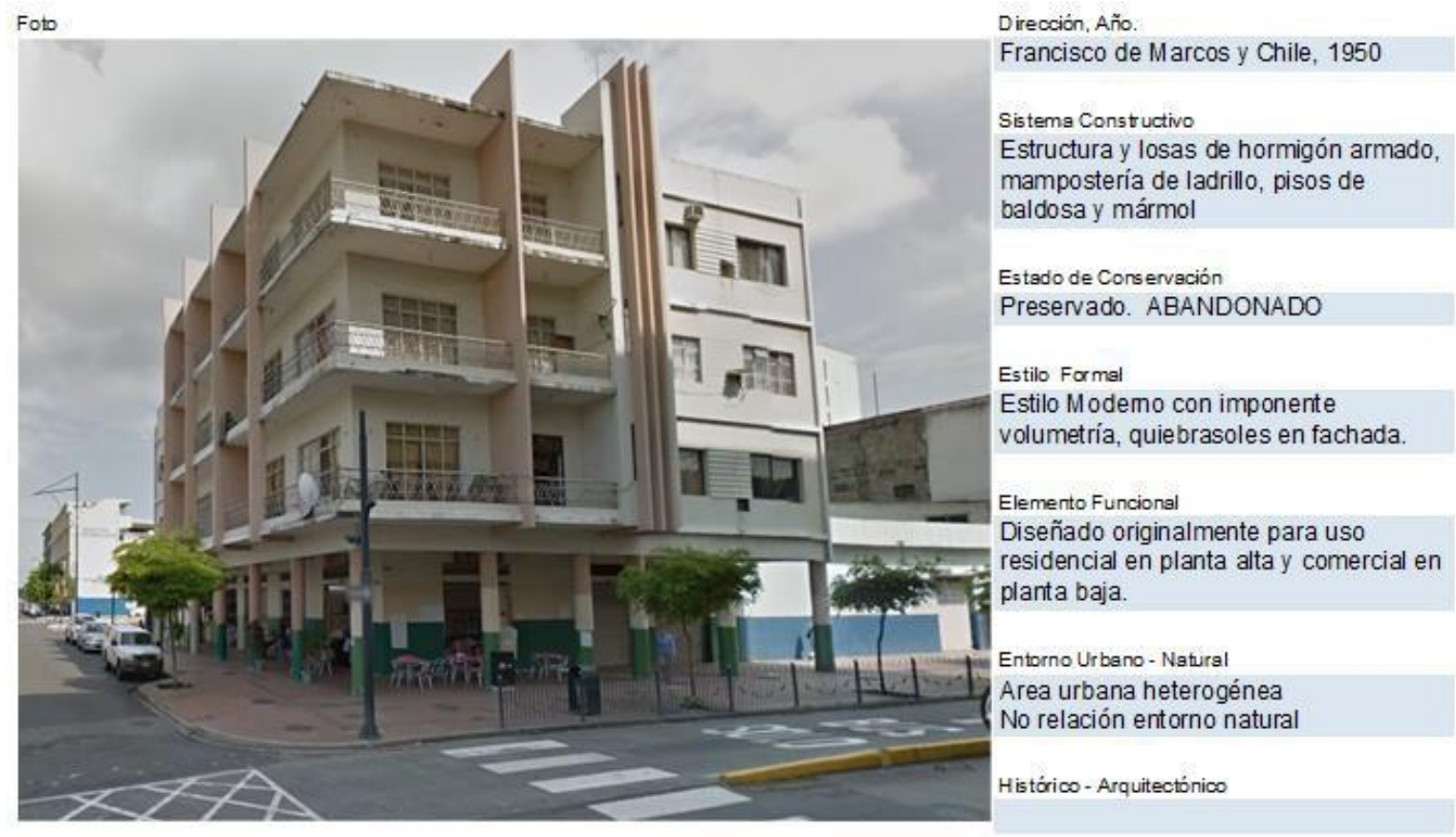

FICHA 12

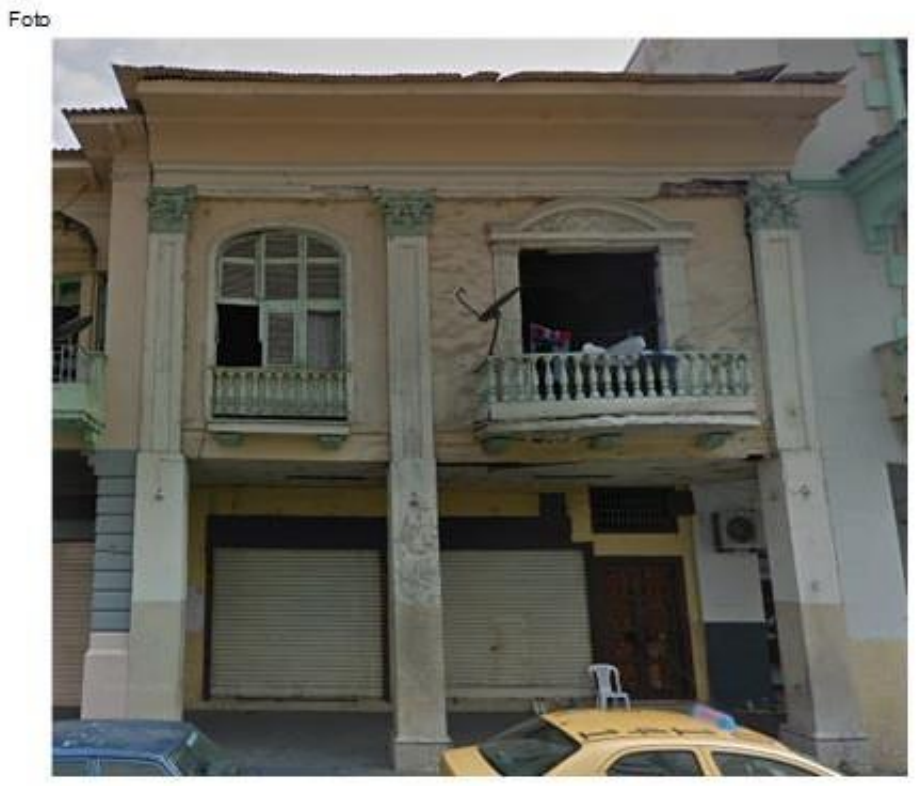

Dirección, Año.

V.M. Rendón 226 Pedro Carbo, 1925

Sistema Const uctivo

Estructura de madera, paredes de

quincha, piso entablado

Estado de Conservación

DETERIORADO

Estilo Formal

formales neoclásicos. Fachada

asimétrica.

Elemento Funcional

Diseñado originalmente para uso

residencial y comercial

Entorno Urbeno - Natural

Area urbana heterogénea

No relación entorno natural

Histórico - Arquitectónico

valor por antiguedad 
Implementación del rescate de edificios que son clasificados como patrimonio arquitectónico histórico de la ciudad de Guayaquil

FICHA 13

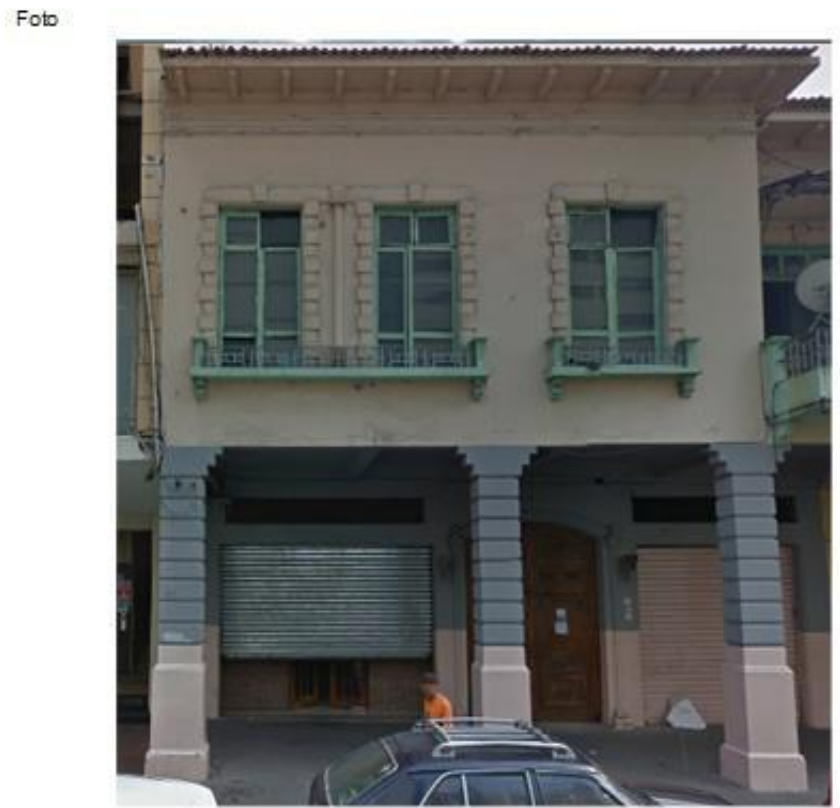

Dirección, Año.

V.M. Rendón 222 Pedro Carbo, 1930

Sistema Constructivo

Estructura de madera, paredes de

quincha, piso entablado

Estado de Conservación

DETERIORADO. ABANDONADO

Estilo Formal

formales neoclásicos. Fachada

asimétrica.

Elemento Funcional

Diseñado originalmente para uso

residencial y comerdal

Entorno Urbano - Natural

Area urbana heterogénea

No relación entorno natural

Histórico - Arquitectónico

Valor funcional y formal histórico 
María C. Sotomayor-Navarro; Magaly N. Sánchez-Lascano; Santiago F. Tisalema-Sáenz; José R. Escobar-Pérez

\section{FICHA 14}

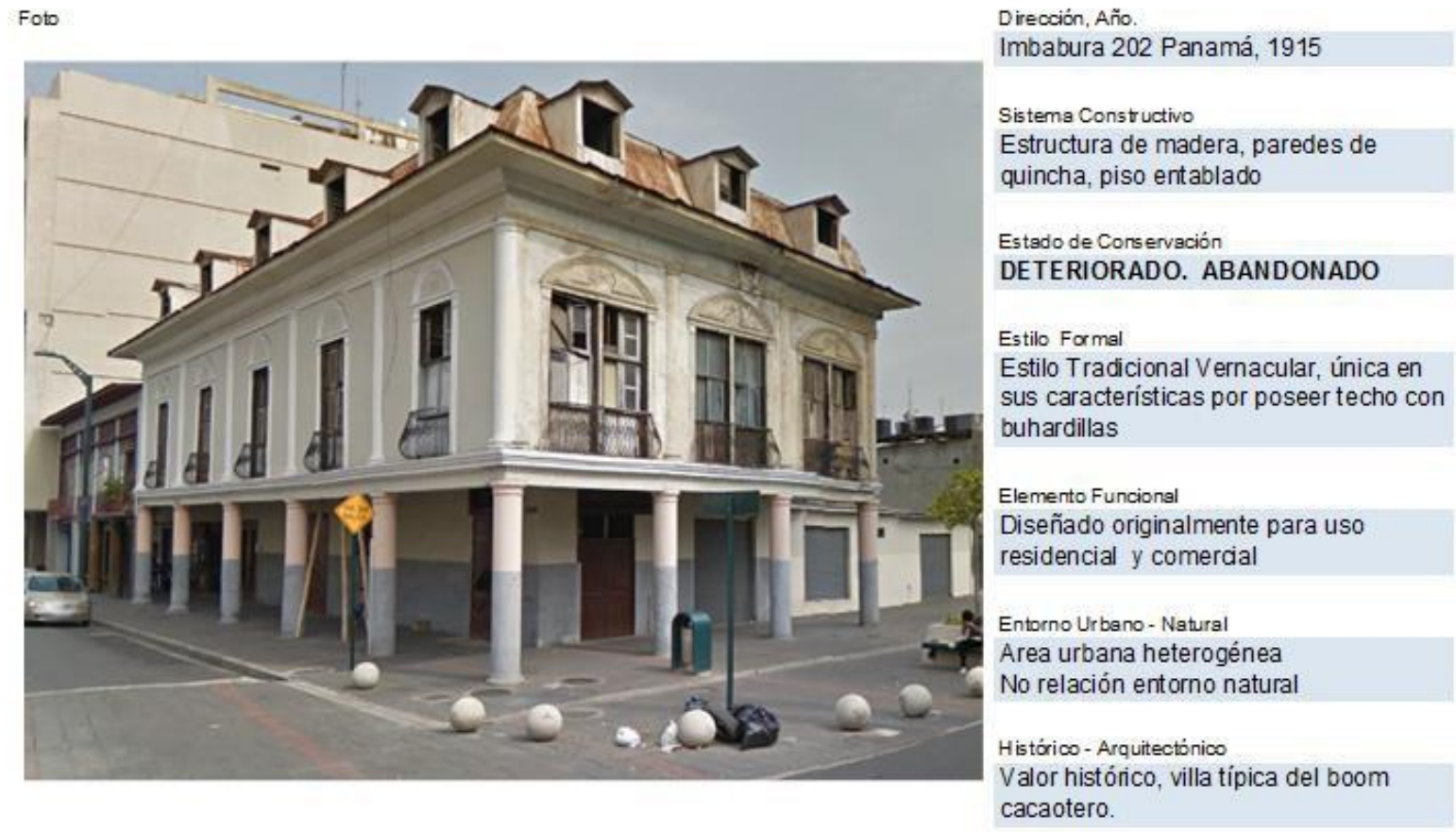

\section{FICHA 15}

Foto

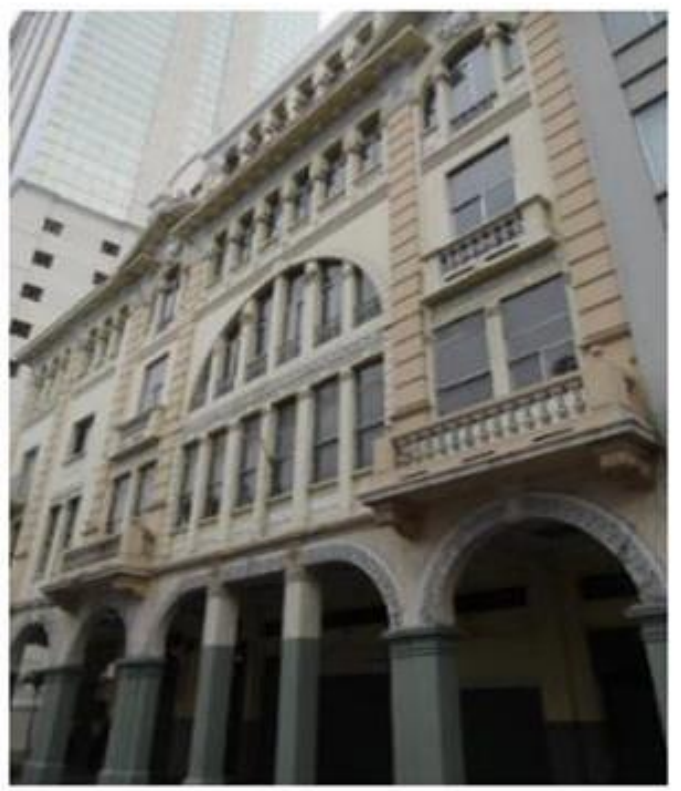

Dirección, Año

Malecón 1009 V.M. Rendón, $1925-1930$

Sistema Constructivo

Estructura y losas de hormigón armado, mamposteria de ladrillo, pisos de baldosa y mármol

Estado de Conservación

DETERIORADO. ABANDONADO

Estilo Formel

Estilo renacentista, con elementos formales: mésulas, frontones, cornisas, arcos medio punnto.

Elemento Funcional

Diseñado originalmente para uso residencial

Entorno Urbeno - Natural

Area urbana heterogénea

No relación entorno natural

Histórico - Arquitectónico

Valor funcional y formal histórico 
Implementación del rescate de edificios que son clasificados como patrimonio arquitectónico histórico de la ciudad de Guayaquil

\section{FICHA 16}

Foto

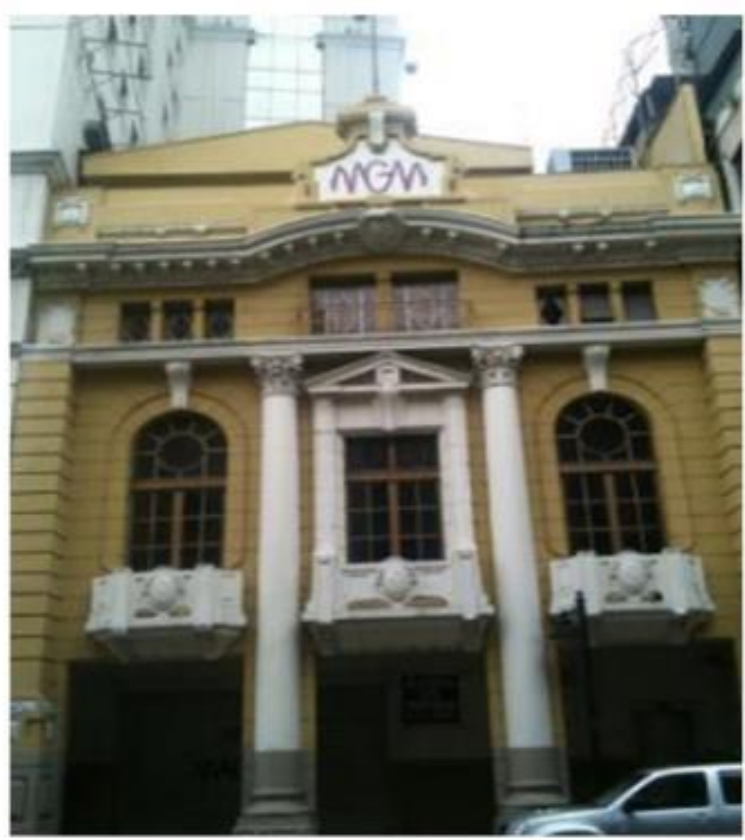

Dirección, Año.

P. Icaza 111 Malecón, 1938

Sistema Const uctivo

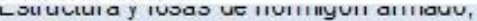
mampostería de ladrillo, pisos de baldosa y granito fundido con

niemmonten

Estado de Conservación

PRE SERVADO. ABANDONADO

Estilo Formal

Estilo republicano con influencias neoclásicas, con elementos formales: arcos medio punto, frontones, capiteles corintios.

Elemento Funcional

Diseñado originalmente para uso de servicios bancarios

Entorno Urbeno - Natural

Area urbana heterogénea

No relación entorno natural

Histórico - Arquitectónico

Valor funcional y formal histórico

\section{FICHA 17}

Foto

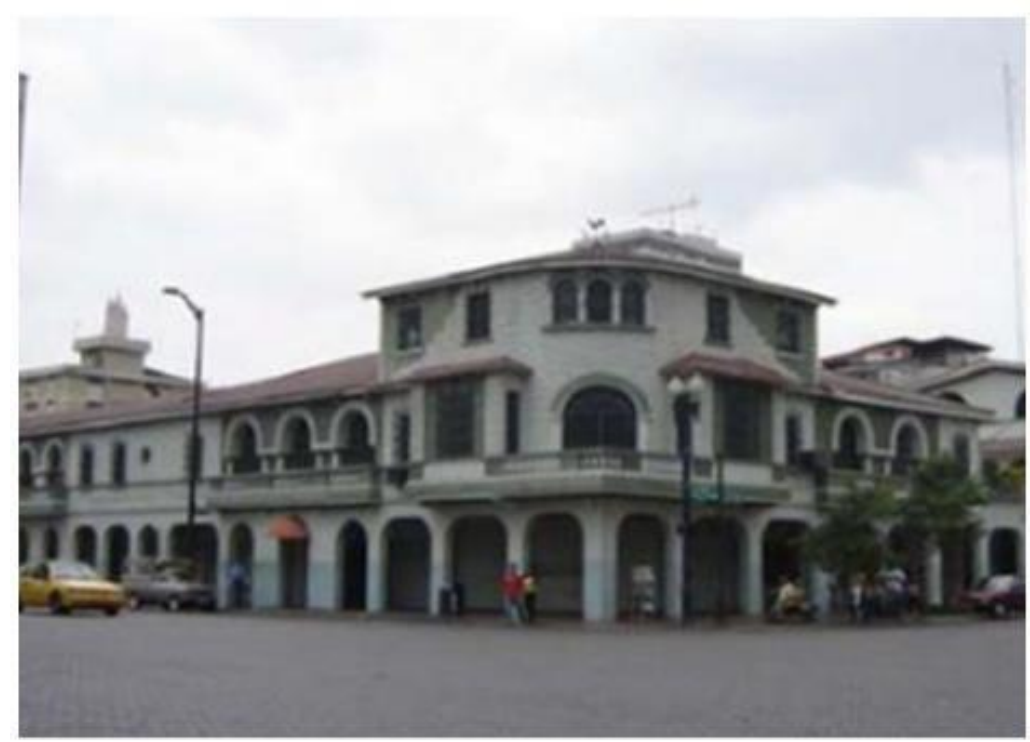

Dirección, Año

9 de Octubre y Quito, 1938

Sistema Const uctivo

Estructura y losas de normigon armado,

mampostería de ladrillo, pisos de

baldosa y granito fundido con

ninmentos

Estado de Conservación

DETERIORO EN SU INTERIOR

Estilo Formal

Estilo republicano con influencias neorománica, con elementos formales: arcadas, balcones balaustrados, ménsulas

Elemento Funcions

Diseñado originalmente para uso

residencial y comercial

Entorno Urbano - Natural

Area urbana heterogénea

No relación entorno natural 


\section{FICHA 18}

Foto

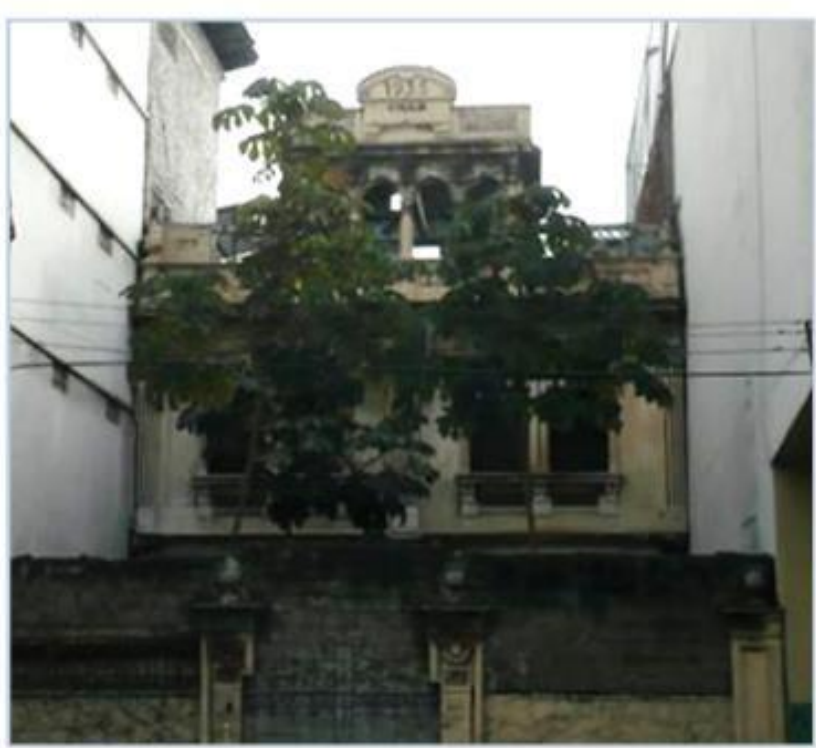

Dirección, Año.

Colón 1222 Av. Quito, 1935

Sistema Const uctivo

Construcció mixta: estuctura y piso de madera, mamposteria de ladrillo

Estado de Consenvación DEGRADADO. ABANDONADO

\section{Estilo Formal}

Estilo ecléctico, con influencia de estilo renacentista y neoclásico

Elemento Funciongl

Diseñado originalmente para uso residencial

Entorno Urbano - Natural Area urbana heterogénea

No relación entorno natural

Histớico - Arquitectónico Valor funcional y formal histórico 
Implementación del rescate de edificios que son clasificados como patrimonio arquitectónico histórico de la ciudad de Guayaquil

\section{FICHA 19}

Foto

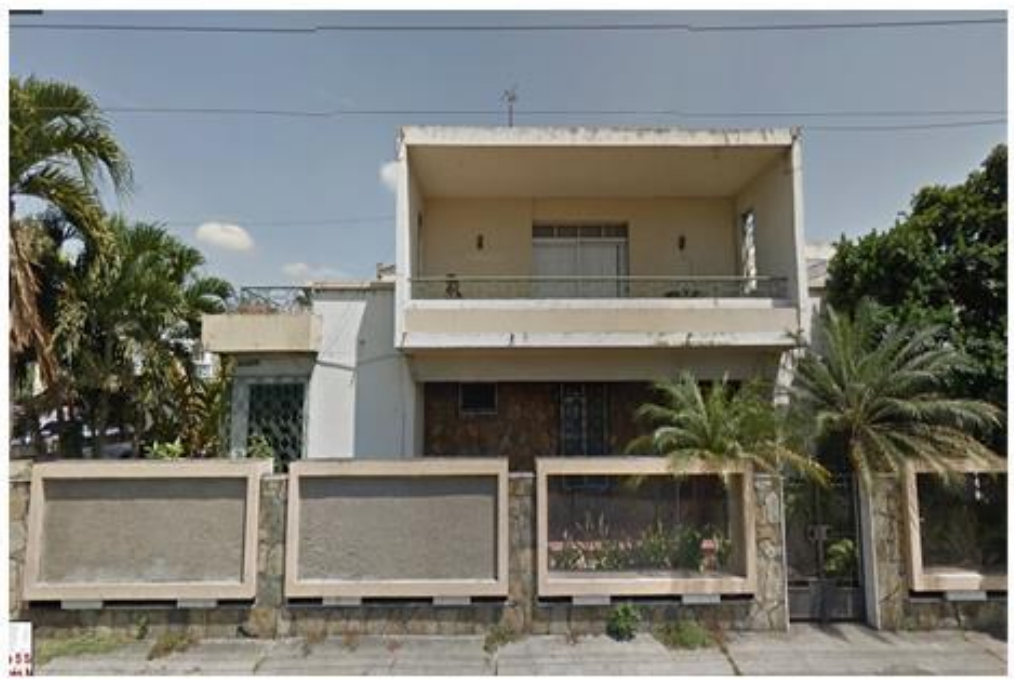

Dirección, Año.

Clemente Ballén 2516 y Andrés Marín, 1940

Sistema Constructivo

Construcción hormigón armado y mampostería de ladrillo, piso de baldosa.

Estado de Conservación INICIAL

Estilo Formal

Estilo moderno purista, presenta juego de volúmenes

Elemento Funcional

Diseñado originalmente para uso residencial

Entorno Urbano - Natura

Area urbana heterogénea

No relación entorno natural

His tórico - Arquitectónico

Valor funcional y formal histórico

\section{FICHA 20}

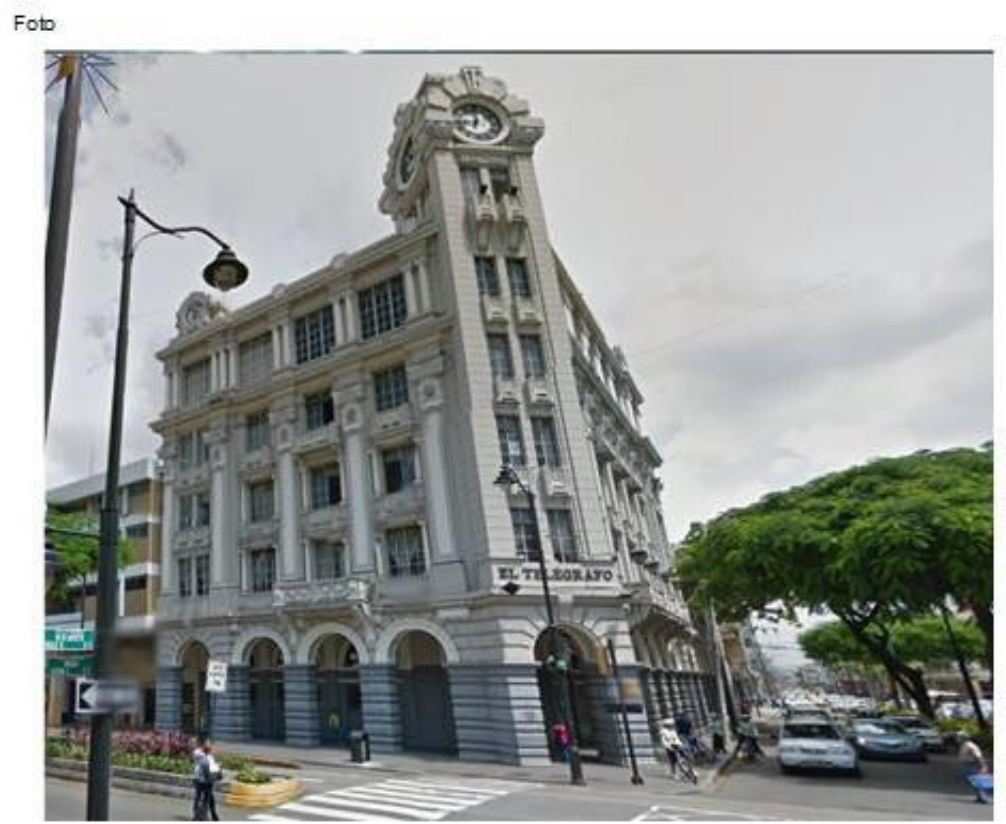

Foto

Dirección, Año.

Edificio Diario El Telégrafo. 10 de

Agosto 601 y Boyacá 1924

Sistema Constructivo

Construccion hormigon armado y

mampostería de ladrillo, piso de

haldnsa

Estado de Conservación

DETERIORADO Y ABANDONADO

Estilo Formel

Estilo republicano con influencia neoclasicista. Escala monumental. Destacado recurso del reloj en el ochave esquinero.

Elemento Funcional

Diseñado originalmente para uso de servicios. Prensa

Entorno Urbano - Natural

Area urbana heterogénea No relación entorno natural

His tớrico - Arquitectónico

$\checkmark$ alor funcional y formal histórico. Hito urbano 


\section{Resultados.}

Se procedió a realizar un análisis del estado de conservación de todos los bienes inmuebles patrimoniales circunscritos en Guayaquil y que se encuentran inscritos en el registro del INPC, de los cuales se seleccionaron los que presentaban estados de abandono, deterioro y degradación. De esta selección se realizó una clasificación de los bienes arquitectónicos que necesitan con urgencia la gestión de preservación cuyas estrategias y medidas ayuden a recuperar el buen estado a estas edificaciones.

Corresponden a casas y edificios que por su gran valor histórico y arquitectónicos no deben dejarse a su suerte hasta llegar a la destrucción total, sobre todo si existe respaldo legal en la Constitución que responsabilicen de esta gestión a entidades administrativas legales.

No obstante, el marco legal en cual se justifica la preservación patrimonial (la Constitución de la República) parece no ser suficiente para que se tomen las medidas necesarias y pertinentes por parte del municipio. En décadas anteriores esta entidad local ha dejado literalmente caer en pedazos casas patrimoniales y otras con alto valor artístico, cultural e histórico, solo por el hecho de estar en mal estado por ser vetustas. Con esta suerte corrieron las casas que se encuentra actualmente en el conjunto patrimonial Parque Histórico (vía a Samborondón), en el cual se recogieron todas las piezas de las casas derribadas por vetustez y las trasladaron al Parque Histórico, que está localizado fuera de los perímetros urbanos de Guayaquil, en el cantón Samborondón, pasando el Río Guayas.

Existen edificaciones que actualmente están abandonadas y deteriorándose en su estructura, fachadas, losas, cubiertas, entre otros elementos, en los cuales no se han tomado ninguna clase de medidas ni gestión para la restauración de estos. Algunos casos, como los de los edificios públicos 
El Frutal y El Telégrafo y la Previsora, que pertenecen al Municipio de Guayaquil, presentan deterioro en chazas de ventanas, puertas, mampostería, pintura.

Edificaciones como los de las fichas 12, 13, 15, 18, que se presentan como abandonadas, están sufriendo del paso inclemente del tiempo al no recibir oportunamente trabajos periódicos de mantenimiento, llevándolos hacia una eminente degradación en el futuro.

\section{Conclusiones.}

Los patrimonios arquitectónicos de la ciudad de Guayaquil se enfrentan con el constante peligro de abandono, degradación física, falta de mantenimiento o hacinamiento, en especial las que se encuentra en el sector céntrico de la ciudad.

La migración rural a la ciudad causa que muchas veces se produzcan sobrepoblación de los centros históricos promoviendo la densificación y hacinamiento en los mismos. Esto con el tiempo y con la falta de mantenimiento y cuidado de las edificaciones, produce una destrucción paulatina del mismo, el cual, sin el cuidado necesario, resulta en la pérdida completa del bien potencialmente patrimonial.

Las ciudades-centros históricos, o también conocidos como cascos antiguos, con todo el complejo de edificaciones, plazas y monumentos que las integran, son considerados de riqueza histórica y cultural invaluable, lo cual, mediante ellos, se puede conservar la identidad original de las ciudades ante el crecimiento y desarrollo que se viven en esta época contemporánea (UNESCO, 2016). 
María C. Sotomayor-Navarro; Magaly N. Sánchez-Lascano; Santiago F. Tisalema-Sáenz; José R. Escobar-Pérez

Es por esto que su conservación y preservación son muy importante, y es necesario mantener o adoptar una política que garanticen la seguridad patrimonial. Por lo tanto, la conservación patrimonial debe ser prioridad dentro de un plan o documento regulador de planificación urbana y local. De esta manera se asegurará la transmisión del valor histórico, cultural o artístico, de generación en generación, procurando no alterar su contenido, valor o imagen, tal como lo expresa John Ruskin (UNIBA,2017).

Actualmente en la mayoría de los países americanos persisten problemáticas similares en los centros históricos o en sus bienes patrimoniales ya sean de índole arquitectónicos, culturales, históricos, tales como el proceso de migración masiva desde zonas rurales, movilidad y segregación social produciendo hacinamiento y abandono en estas áreas, los mismos que adolecen de bajo mantenimiento de los inmuebles. También suele existir un conflicto latente entre las antiguas estructuras viales y el desarrollo y recorrido de los medios de transporte actuales, realización inadecuada de obras públicas y expansión no regulada de actividades terciarias.

La conservación integral de los patrimonios arquitectónicos y urbanos, debe ser regulada de manera oficial por instituciones y órganos locales o regionales por medio de un documento planificador y regulador de preservación y conservación de patrimonios históricos, con el cual se trabaje integralmente con planes directores de desarrollo urbano y regional. De esta manera se podrá garantizar la conservación, preservación, revitalización y revaloración de estos elementos y lugares patrimoniales, así como también el mejoramiento de la calidad de vida de la población directamente vinculada a estos, procurando el uso equilibrado de tecnología tradicional con la actual y contemporánea. 
Se ha de buscar siempre la promoción de la rehabilitación de los patrimonios arquitectónicos urbanos, así como también de los centros históricos, tratando de respetar y potencializar la identidad histórica-social, cultural, artística de la ciudadanía guayaquileña que evidencia el desarrollo de la ciudad en sus diferentes contextos de desarrollo.

El Instituto Nacional de Patrimonio Cultural, INPC, Regional 5, dispone un inventario de bienes arquitectónicos patrimoniales registrados en la Guayaquil. Tras un trabajo minucioso realizado durante el año 2010, en un esfuerzo en conjunto entre los arquitectos Compte, Lee y Peralta, y con el apoyo de las Universidades de Guayaquil y Católica, lograron aumentar este inventario, de 300 bienes inmuebles en perímetro urbano registrado hasta el 2010, a 637 bienes inmuebles en el 2011, superando el $100 \%$ de lo que se contaba anteriormente. En el nuevo inventario se aprecian los siguientes resultados:

Se consideran cuatro nuevas áreas patrimoniales consolidadas: Barrio del Salado, Barrio Orellana, Barrio Urdesa, Barrio Centenario

- Se consideran alrededor de 300 nuevos hitos arquitectónicos y urbanos que representan valores arquitectónicos favorecedores de memoria colectiva e identidad de la urbe

- El área del inventario de bienes patrimoniales arquitectónicos apenas constituye el 4,30\% al área total urbano de Guayaquil

- No existe CENTRO HISTORICO consolidado en la ciudad de Guayaquil, como los que poseen ciudades como Quito y Cuenca. Se registran en el centro de la urbe dos núcleos arquitectónicos-urbanos, los mismos que constituyen áreas patrimoniales consolidadas: Barrios Las Peñas y Río Guayas 
- Existen tres núcleos arquitectónicos-urbanos, constituyen áreas patrimoniales consolidadas en sector norte: Barrios El Salado, Orellana, Urdesa Central. Un núcleo arquitectónicourbano, constituyen áreas patrimoniales consolidadas en sector sur: Barrio Centenario

\section{Cuadro de núcleos y elementos patrimoniales de Guayaquil}

\begin{tabular}{|c|l|c|c|}
\hline BIEN PATRIMONIAL & \multicolumn{1}{|c|}{ DESCRIPCION } & LOCALIZACIÓN & AREA APROXIMADA \\
\hline Barrio Las Peñas & $\begin{array}{l}\text { Area patrimonial consolidada a manera de núcleo } \\
\text { urbano, con hitos arquitectónicos construidos desde } \\
1915 \text {. Calle principal, Numa Pompilio Llona tiene una } \\
\text { longitud de aproximadamente } 400 \text { metros }\end{array}$ & Sector céntrico-norte & $12.000 \mathrm{~m} 2$ \\
\hline Barrio Río Guayas & $\begin{array}{l}\text { Area patrimonial consolidada, construida en 1929. } \\
\text { Abarca edificaciones emblemáticos como Palacio de la } \\
\text { Gobernación, Palacio Municipal, Catedral, Torre } \\
\text { Morisca y un conjunto de primeras casas de estilo } \\
\text { republicano construidas en el sector. }\end{array}$ & Sector centro & $51.400 \mathrm{~m} 2$ \\
\hline Barrio Centenario & $\begin{array}{l}\text { Consolidación de Hitos arquitectónicos y urbanos con } \\
\text { áreas consolidas urbanas patrimoniales, cuyas } \\
\text { construcciones datan desde 1923, respetando los } \\
\text { criterios racionalistas de esa época }\end{array}$ & Sector sur & $396.000 \mathrm{~m} 2$ \\
\hline Barrio Urdesa & $\begin{array}{l}\text { Area patrimonial que contiene Hitos arquitectónicos } \\
\text { patrimoniales. Valores arquitectónicos de estilo } \\
\text { racionalista, desarrollado en la década de 1950 }\end{array}$ & Sector Norte- centro & $1.60 \mathrm{~km} 2$ \\
\hline Barrio del Salado & $\begin{array}{l}\text { Area urbana patrimonial consolidada, sin regulación } \\
\text { municipal de preservación patrimonial }\end{array}$ & Sector Norte- centro & $280.000 \mathrm{~m} 2$ \\
\hline Barrio Orellana & $\begin{array}{l}\text { Area consolidada patrimonial, no tiene regulaciones } \\
\text { por parte del Municipio para su conservación y } \\
\text { preservación }\end{array}$ & Sector Norte- centro & $670.000 \mathrm{~m} 2$ \\
\hline Hitos arquitectónicos & $\begin{array}{l}\text { Edificaciones inventariadas por el INPC de caracter } \\
\text { selectivo ubicadas en varias zonas céntricas de la } \\
\text { ciudad. A lo largo de avenidas y calles como: } 9 \text { de } \\
\text { Octubre, Malecón Simón Bolivar, Luque, Aguirre, } \\
\text { Rumichaca, 10 de Agosto, Pedro Carbo, Julián Roca, } \\
\text { Av Olmedo, Noguchi, 6 de Marzo, Victor Manuel } \\
\text { Rendón }\end{array}$ & Sector céntrico - norte - sur & \\
\hline
\end{tabular}

El análisis de este inventario nos indica que Guayaquil no cuenta con un gran Centro Histórico consolidado y unificado como Quito o Cuenca. Sus bienes patrimoniales se encuentran focalizados en núcleos urbanos de poca densidad poblacional, y la presencia de hitos arquitectónicos y urbanos de característica selectivo disperso dentro del sector céntrico de la urbe.

También indica la imperante necesidad de la ciudad de contar con un Plan Regulador Patrimonial Municipal, en el cual se establezcan directrices específicas sobre el ordenamientos de las zonas de núcleos arquitectónicos- urbanos y de hitos arquitectónicos que realmente garanticen la 
Implementación del rescate de edificios que son clasificados como patrimonio arquitectónico histórico de la ciudad de Guayaquil

conservación de la identidad histórica de la ciudad por medio de la preservación patrimonial arquitectónico.

La falta de iniciativa de actuaciones de preservación y conservación por parte del Municipio de Guayaquil y el INPC permiten que se deterioren construcciones de alto valor histórico y de vital importancia para resguardar la identidad de la población Guayaquileña. Por esta razón surge la demolición indiscriminada de edificaciones por parte del Municipio, justificándose por presencia de edificación vetusta u obsoleta, para construir otros nuevos, sin contemplación en de tipología arquitectónica de identidad, o lo transforman en solares vacíos para estacionamientos.

La regulación de bienes inmuebles patrimoniales en Guayaquil es considerada muy generalizada y escasa debido a que no existe un documento legal, regulador consistente que defina parámetros más específicos para la realidad de la ciudad. Existen ordenanzas de grupos de bienes patrimoniales aislados, mas no se toma en consideración la totalidad de los bienes inmuebles registrados como patrimonio por el INPC, por lo tanto existe una necesidad de revisión y mejoramiento de los planes reguladores urbanos, que mejoren la falta de control por parte del Municipio en los usos del suelo, formas de ocupación y edificación en áreas patrimoniales que se vive actualmente.

\section{Bibliografía:}

1. AYALA, Carlos. LA TEORIA E HISTORIA CRITICA DE LA ARQUITECTURA EN LATINOAMERICA. LOS ESTUDIOS DE LOPEZ RANCEL Y ROBERTO SEGRE. Tesis Facultad de Arquitectura. USAC Guatemala. 1991.

2. GOMEZ, José. Artículo “EL PAISAJE URBANO DE GUAYAQUIL”. ANTOLOGIA HISTORICA. 2000. FLACSO. Quito, Ecuador

3. HOLM, Olaf. LA ARQUITECTURA PRECOLOMBINA. Ecuador.

4. INSTITUO NACIONAL DE CULTURA. Cuzco. Cartas Internacionales de Conservación de Patrimonio 
María C. Sotomayor-Navarro; Magaly N. Sánchez-Lascano; Santiago F. Tisalema-Sáenz; José R. Escobar-Pérez

Cultural. Perú 1991.

5. LEE, Pablo; COMPTE, Florencio; PERALTA, Claudia. PATRIMONIO ARQUiTECTONICO Y URBANO DE GUAYAQUIL. Ed. Universidad Católica de Guayaquil. Facultad de Arquitectura. Guayaquil. 1989

6. LEE, Pablo. TESTIMONIO Y MEMORIA DE LA ARQUITECTURA HISTORICA DE GUAYAQUIL. 1996. Ed. Universidad Católica de Santiago de Guayaquil. Guayaquil, Ecuador.

7. LOIS, Gonzalo; PIÑEIRA, María José. GOBERNANZA EN CASCOS HISTORICOS PATRIMONIOS DE LA HUMANIDAD: CASO DE QUITO (ECUADOR). España, 2010

8. LOIS, Rubén; PIÑEIRA, María José. GOBERNANZA EN CASCOS HISORICOSPATRIMONIO DE LA HUMANIDAD: EL CASO DE QUITO - ECUADOR. Las escalas de la geografía del mundo: Homenaje al profesor Miguel Panadero Moya. Ed. Servicio de Publicaciones de la Universidad de Castilla-La Mancha. España. 2010

9. ROJAS, Milton; VILLAVICENCIO, Gaitán. EL PROCESO URBANO DE GUAYAQUIL 1870 - 1980. Ed. Ildis Cer-G. Ecuador

10. UNIBA. (2017). Patrimonio Urbano. DESTRUCCIÓN, CONSERVACIÓN Y RENOVACIÓN. UNIVERSIDAD DE BARCELONA, 2017 